\title{
An Ecologic Approach to Chinese Traditional Ethnic Sports Education
}

\author{
Xin Zhang, Siyong Xia \\ Department of Physical Education, Southwest University, Chongqing, China \\ Email: 1678146313@qq.com \\ Received 20 January 2015; accepted 10 February 2015; published 11 February 2015 \\ Copyright $@ 2015$ by authors and Scientific Research Publishing Inc. \\ This work is licensed under the Creative Commons Attribution International License (CC BY). \\ http://creativecommons.org/licenses/by/4.0/

(c) (i) Open Access

\begin{abstract}
This research aims to discuss and explore, from the perspective of Ecologic Education, the ecologic characteristics of the traditional Chinese sports education and the developmental direction of the teaching model of Chinese traditional ethnic sports education under the guide of the view of Ecologic Education. Firstly, this research explores the background of the appearing of the view of Ecologic Education and the basic ideas of Ecologic Education. After that, the writer of this article comes up with the ecologic characteristics particularly embraced in Chinese traditional ethnic sports education. These characteristics or features include the educational aim of pursuing harmony, the developmental model of advocating co-existence, the knowledge view of cultural circumstance, and the interactive and win-win relationship between teachers and students. After the analysis made above, the writer of this article further argues that under the view of Ecologic Education pursuing life education full of spirituality, focusing on the active construction of knowledge and exploring multiple ways of enculturation can be the very direction of the teaching model of Chinese traditional ethnic sports education.
\end{abstract}

\section{Keywords}

The View of Ecologic Education, Traditional Ethnic Sports Education, Teaching Model, Harmony, Co-Existence

\section{Introduction}

The Belgrade Charter in 1975 and the Tbilisi Declaration in 1977 symbolized the foundation of Ecologic Education. In 1992 UNCED passed Agenda 21 in which there was a specialized chapter to discuss the environmental and ecologic educational problems, which was a measure promoting the development of Ecologic Education. In the 21 st century, ecologic crisis has become a tough problem that hinders the development of the world, hig- 
hlighting the importance and emergency of implementing Ecologic Education. The aim of this research article is to form a valid and credible approach to the construction of the teaching model of Chinese traditional ethnic sports education by discussing the ecologic characteristics of the traditional Chinese sports education and exploring the developmental direction of the teaching model of Chinese traditional ethnic sports education from the perspective of Ecologic Education or under the guide of it.

\section{Understanding of the View of Ecologic Education}

\subsection{Ecologic Education Prompted by Ecologic Crisis}

Ecologic crisis has always been one of world's hottest issues. People's knowledge about ecologic crisis stays on such problems as environmental pollution, green-house effect, extinction of species, sharp increase of population, shortage of natural resources and the like, all of which result from the predatory exploitation of nature. However, all those aspects just comprise of the overt part of ecologic crisis. The deeper crisis lurking beneath is the very crisis of humanity itself.

Ecology consists of three layers, namely, the ecology of nature, the ecology of society and the ecology of humanity itself. Then the ecologic crisis covers all these three layers. The ecologic crisis existing in human spirit is the most important factor that leads to other various crises. Ecologic crisis originated in the western industrial revolution and has become a global problem with the worldwide industrialization. It is safe to say that the origin of ecologic crisis lies in the western world and the root of it lies in the view of the relationship between human and nature. From the perspective of the traditional western philosophy, the dichotomy of subjectivity and objectivity imposed by those western philosophers like Descartes argues for the opinion of factitious division between human and nature. The early modern natural view characteristic of mechanism treats nature as lifeless and vulnerable to will. It also holds that the relationship between human and nature is the sheer one between subject and object, namely, the "I-it" relationship (Su, 1998); in the view of the traditional religion of western world, the Christianity developed in the western world is the religion having the strongest human-centered color that ever exists in the world (White, 1993). The Christian religion believes that human is the highest work by the God, created in accord with the "image of God", so human beings are spontaneously endowed with the rights to rule the other creatures; analyzing from the perspective of western ethics, we may find that the traditional western society supports the individual-centered ethic opinion and the banner of human rights flies high. They hold that the individual rights are above the collective and social ones and that an individual can pursue the maximum of his or her interests only if no others' interests are infringed upon. This isolated, atomistic view from the optimistic aspect extends to the largest degree the human value or from the pessimistic aspect guarantees the survival of human beings and all kindness is still the concrete kindness to humans while nature is only an affiliation (Rolston, 2000). Under such a background of philosophic views, religious ideas and ethic thoughts, the relationship between human and nature is doomed to be fragmented, twisted and apathetic. In this case, their attitude towards nature is of course cruel and predatory. When such view of value is projected on the dealing with the interpersonal relationship and with the other-and-self relationship, the emergence of ecologic crisis in society and in individual is inevitable. So the root of ecologic crisis lies in the crisis of humanity itself, or more specifically, the crisis of human spirit. To solve the spiritual problems, education assumes an obligatory responsibility. When the British economist E. F. Schumacher in his Small Is Beautiful discusses about addressing ecologic problems, he strongly supports the idea that education is the largest resource and the principal task of education is to instruct the view of value and to instruct how to treat life (Schumache, 1984). Thus, the ecologic crisis prompts the implementation of the Ecologic Education.

\subsection{Basic Ideas of the View of Ecologic Education}

The concept of "ecology of classroom" was first proposed by the US educationist W. Waller in The Sociology of Teaching in 1932 (Bogdan \& Biklen, 2003). When people gradually become aware of and pay attention to ecologic crisis, Ecologic Education today has become a trend of the development of current education. Besides, the view of Ecologic Education is becoming more and more popular. The view of Ecologic Education is based upon the ecologic philosophy which holds that the essence of the world is a compound ecologic system of "human-nature-society" and the view supports the idea of the organic cognitive model. Upon such foundation, the basic ideas of the view of Ecologic Education are the followingS: the educational aim of developing complete 
personality; advocating the networked and open knowledge system; educational method focusing on dynamic situation; advocating equal and harmonious relationship between the teacher and students.

\section{Characteristics of Traditional Ethnic Sports under the View of Ecologic Education}

Many ideas of ecology are well interpreted in the traditional ethnic sports when people analyze the traditional ethnic sports in the dimension of Ecologic Education. First of all, the compound ecologic view of "human-nature-society" is in accord with the idea of unity of heaven and man or the idea of "the co-existence between the world and individual and the integration of all things and individual" implied in the traditional ethnic sports of China. To be specific, under the view of Ecologic Education, the traditional ethnic sports contain the following features.

\subsection{The Educational Aim of Pursuing Harmony}

The traditional ethnic sports first pursue the harmony of human and nature. The traditional culture of China heavily focuses on the organic view of harmony or the idea of "integration of all things and individual". Meanwhile, the traditional ethnic sports are rooted in the small-scale rural natural economic base and many origins of sports are related with the rite for harvest and worship of gods. Sports such as five-animal exercises, qi gong and tai chi reflect the idea of "respecting the natural way and preserving the natural body". The traditional ethnic sports also pursue the harmony of human and society. "Courtesy" is one of the key cultural characteristics in China and the traditional ethnic sports highlight the idea that "morals are prior to craftsmanship and morals show themselves in craftsmanship". From the idea of the ritual archery "understanding the courtesy among monarch and subjects and understanding the order of the elder and the younger" to the Chinese martial arts saying "judging the heart by literacy while judging the morals by the use of force", all present the characteristic of moral requirement in traditional ethnic sports while morality is the key factor that adjusts and maintains the interpersonal harmony and the harmony of human and society. The traditional ethnic sports pursue the harmony of humanity itself. The traditional sports ideas of health keeping take a special place in the traditional sports culture of China. They are deeply rooted in the tradition of Chinese health keeping which follows the organic view, focusing on internal and external cultivation as well as integration of spirit and form and pursuing the dynamic balance of body and mind. In this case, it avoids the compensatory side effects to body and mind resulting from the blindly pursuit of being "faster, higher and stronger" in western competitive sports.

The educational aim of traditional ethnic sports is to pursue harmony and such kind of harmony is a comprehensive one, reflecting the harmony view of the integration of human, nature and society.

\subsection{Advocating the Developmental Model of Co-Existence}

Co-existence is a very vital concept in Ecologic Education. It mainly contains two levels in education: the coexistence of human and nature as well as that of all the various cultures. The co-existence of human and nature means the harmony between human and nature, a point having been argued in the former part of this paper. The co-existence of various cultures generally refers to the ideas of "living by oneself" and "behaving oneself" as well as the way of co-existing with other nations and diverse forms of cultures.

The traditional ethnic sports of China have a long history of several thousand years. Many traditional ethnic sports survive the time due to the developmental model of the cultural co-existence. That "greatness lies in capacity" and the idea "harmony without uniformity" represent the ever national spirit of China, creating the foundation of the developmental model of the cultural co-existence in traditional ethnic sports.

Concerning the sports education within schools of China, how to deal with the relationship between the traditional Chinese sports and the modern western sports is always a hot topic in the academic field. The strategy of "becoming a cultural power" imposed at the sixth Plenary Session of the 17th CPC Central Committee has made the topic more practical and urgent. The view of Ecologic Education advocates the cultural view of multiple coexistence and holds that different cultures belong to the heterogeneous and isomeric body which facilitates the production of new materials and new matters, preventing the tendency of cultural homogenization which is becoming more and more serious. Within school sports, we should actively explore the developmental models of the co-existence between traditional ethnic sports and modern sports of the western world, which is beneficial 
for the inheritance and innovation of our traditional ethnic sports as well as the sharing of the excellent cultural fruit of all human beings.

\subsection{The Knowledge View of Cultural Circumstance}

For the perception of knowledge, the view of Ecologic Education first holds that knowledge is culture rather than "code". In the process of instructing knowledge, if it is only the abstract code vehicle that is presented by depriving of the cultural soil that knowledge is dependent on and by abandoning the rich cultural meanings, such type of knowledge instruction is lifeless and empty and cannot evoke the emotional resonance and the rational identity (Zhu \& Peng, 2009). The knowledge of traditional ethnic sports is comprehensive and its system contains various kinds of direct, rich and stylized body movements and all kinds of value knowledge such as spiritual faiths, natural views and philosophical thoughts, etc. They all simultaneously exist in one concrete traditional sports program. Thus, the instruction of traditional ethnic sports is cultural rather than pure instruction of body movement. The complete instruction of traditional ethnic sports should focus on both aspects of body movement and spiritual culture and focus on the inheritance of the material aspect of the traditional ethnic sports as well as the cultural soul kept in the traditional ethnic sports, which can inspire and enrich the learning subjects' inner world and help them construct the ecologic world full of spirituality.

The view of Ecologic Education argues that knowledge is circumstantial rather than universal. Knowledge is characteristic of uncertainty, generativity and locality. The traditional ethnic sports are closely related with specific practice of living and production. Both the overt body movements and the covert value knowledge are based upon the cultural factors composed of a certain time, space, historical background and value system. But for the related cultural soil, all will mutate or even disappear. Take archery for example. As an ancient traditional ethnic sports program, it appeared in oriental China and occidental Greece several thousand years ago. But because of the different cultures that it was rooted in, great differences lie in its equipment, exercise modes, rules and views of cultural value. In China, it was a courtesy rite for showing the hierarchy of the monarch and subjects as well as that of the elderly and the young. While in ancient Greece it was a military training for building the body and protecting the country.

The view of circumstantial knowledge holds that the understanding of knowledge is subjective and generative, reflecting the choice and personal interpretation of knowledge by the learning subjects. The learning subjects are in a historical situation and the understanding and mastery of special knowledge are closely related with knowledge structure, view of value, life experience and psyche that the learning subjects have already formed. Dragon boat competition is a traditional ethnic sports program that is fairly well carried out in China. In Hunan province, people carry out this sports program to memorize Yuan Qu for his patriotism while in the western part of Hunan, people do it to worship the dragon for rain and pray for harvest. In Suzhou, people do it to memorize Zixu Wu whose hair all turned white over one night and who was fearless when facing death. The verse by the Tang dynasty poet Shi Li vividly presents the fighting spirit: the rows struggle for the destination; the sails in the foam approach the lotuses. Nowadays, people carry out the sports program mainly for exercising bodies, strengthening collective cohesion and celebrating festival. The shapes and colors of dragon boats and dragon boat raps are different in styles in different areas. When the dragon boat culture enters the sports class, the learning subjects will choose the understanding and comprehension of the culture and take advantage of it. In this case the dragon boat culture transforms from public knowledge into individual knowledge. So the culture of traditional sports can be presented as a circumstantial knowledge either in light of knowledge itself or from the perspective of the learning subjects.

\subsection{The Interactive and Win-Win Relationship between Teachers and Students}

The view of Ecologic Education focuses on the existence of individual as a unique life and the demonstration of living life and focuses the covert, lively and flowing emotionalization of life (Liu, 2000). The view of Ecologic Education is an open educational view, advocating the ecologic teacher-students relationship with mutual respect and equal position in dialogue. The teacher as the chief one in the equal relationship ought to squat and converse with students. While instructing the knowledge, the teacher should pay attention to evoking the subjective initiative of the learning subjects and promote the growth of organic life. Meanwhile, in the equal communication with the learning subjects, the teacher can not only increase his or her wisdom of teaching, but also perfect his or her value systems and improve the level of literacy. So the relationship between teachers and stu- 
dents under the view of Ecologic Education is a new one that is interactive and benefits both sides.

Traditional ethnic sports education pursues the interactive and win-win relationship between teachers and students. The knowledge of traditional ethnic sports is circumstantial. It focuses on the personal interpretation and choice of the knowledge by the learning subjects. Teachers in teaching practice should make efforts to create an environment of teaching and learning that is open and equal and help students understand, master, digest and absorb the knowledge of traditional ethnic sports, which is based upon the necessary and beneficial guidance of knowledge. Understanding the form and meaning is the important content and cultural characteristic of traditional ethnic sports. Take the movements of "white crane spreading its wings" and "parting the wild horse's mane" in tai chi for example. Those technical movements cannot be taught in accordance with the western quantitative criteria while understanding the form and meaning is very personalized, requiring the learning subjects to understand and master it independently. That is why many foreign friends who are fond of tai chi show it with a different western style. And this objectively causes them to interpret and comprehend Chinese traditional ethnic sports in different ways. Another feature of traditional ethnic sports is locality. In actual practice of teaching and learning, some students of minorities can be more familiar and more professional than the teacher concerning the mastery of the traditional native sports, which leads to an interesting phenomenon in which the teacher becomes a student and vice versa. So it is the aim of traditional ethnic sports teaching and learning to pursue the interactive and win-win relationship between the teacher and students, and such pursuit itself is one of the features of the teaching and learning practice.

\section{Teaching and Learning Model of Traditional Ethnic Sports under the View of Ecologic Education}

\subsection{Teaching and Learning Model to Pursue Life Education Full of Spirituality}

Traditional model of teaching and learning of sports focuses on the instruction of the sports skills. In specific practice of teaching and learning, the procedure consists of the demonstration and explanation of movements by the teacher and imitation and exercises by students. After a certain exercise time and amount of exercise, most of students can master the basic movements and incur a certain amount of exercise load so that the aim of exercising body is realized. Such model views students as passive containers and simplifies the practice of teaching and learning into pure skill instruction, weakening the cultural connotation implied in the teaching and learning of sports. With this teaching and learning model that puts skills above culture, the inner worlds of the learning subjects do not receive full respect and enough cultural cultivation. So, how can we go on to talk about the development of human full of rich life energy and with healthy ecologic view? As Whitehead says, a person can understand all the knowledge of the sun, all the knowledge of the air and all the knowledge of the rotation of the earth but this person just cannot see the splendor of the sunset (Doll Jr., 2000).

The teaching and learning of traditional ethnic sports should be under the guide of pursuing spirituality and focus on the existence of each learning subject as living individual. In the process of teaching and learning of traditional ethnic sports, apart from instructing skills, exercising bodies and boosting health, we should also guide the learning subjects to experience and interpret the traditional faiths, pursuit of value and cultural meaning and to integrate with experience and understanding of the real living world, making them contemplate over the relationship of human and nature, of human and culture, of human and society and of human and self and in turn construct their own spiritual home and continuously enrich the spirituality of their lives. Shouyao Teng once said that when human beings pass the industrial civilization and enter the epoch of post-industrial civilization, art is like a cup containing the water of life which is prepared for the dry lips that are far away from nature while suffering from alienation in this epoch (Teng, 2006). The education of traditional ethnic sports should focus on the inner world of the learning subjects and integrate the instruction of techniques and skills with the understanding of cultural value, promoting the learning subjects' realization of life, cognition of self and development of spirituality and thus becoming the real life education.

\subsection{Teaching and Learning Model to Focus on the Active Construction of Knowledge}

The knowledge of traditional ethnic sports of minorities feature in culture and circumstance and the cultural feature and circumstantial one are bound to lead to the uncertainty of knowledge. So each learning subject's understanding of the same knowledge of minorities' traditional ethnic sports is different from others' due to the 
different experience, emotion and religious belief of individuals. There is no unique, authoritative and doubtless answer. As the saying suggests, Hamlet varies from reader to reader. So, the learning subjects are no longer the "negative containers". Teachers also no longer hold the absolutely authoritative power of speech. The learning subjects no longer just receive the input of information but also realize the output of information. The model of teaching and learning should focus on the active construction of knowledge by the learning subjects and encourage them to express and communicate their thoughts freely. Of course the teacher still has the priority power of speech. Above all, the teacher owns more knowledge and information than the learning subjects. Firstly, the teacher needs to offer new information and knowledge to the learning subjects so that the learning subjects can make personal interpretation based upon such materials. This personal interpretation is precious for the modernization of traditional ethnic sports. The inheritance and development of traditional culture cannot go without care for reality. The endowment of modern connotation is necessary. The learning subjects' open and innovative minds are sure to bring forth beneficial thoughts for the development of modernization in traditional ethnic sports. Meanwhile, within such teaching and learning model that encourages expression and creation, the learning subjects not only obtain the true respect but also develop the self-confidence, which plays a positive role in constructing the learning subjects' ecologic value system and ecologic outlook of the world featuring equality and philanthropy.

\subsection{Teaching and Learning Model to Explore Multiple Ways of Enculturation}

Enculturation is an important mechanism for the spread and production of culture. Enculturation means the process of perceiving the traditional ideas and manners by the young people in the same cultural group through conducting the partly conscious and partly unconscious learning under the senior people's direction, guidance or enforcement. Enculturation is a vertical inheritance of culture. With the current process of globalization, the tendency of cultural homogenization is becoming more and more obvious and the western sports culture takes the lead in the global sports cultures. The ecologic view of value advocates the diversity of cultures and holds that all kinds of cultures should have a place to exist and develop in the world. Meanwhile, to construct a culturally powerful country has become the consensus of our society. Under such a historical background it is necessary to strengthen the enculturation of the traditional ethnic sports.

Traditional ethnic education of culture is an environmental education rendering into real life with social education and family education taking the main parts. In this way of education, the ethnic culture passes down mainly by the oral form from generation to generation and the people are influenced by the activities and rites and in turn receive inspiration, making choice with the change of life and consequently promoting the advancement of ethnic culture (Sun \& Li, 2010). The way of enculturation in traditional ethnic sports culture has such features as the type of environment, the type of life and the type of experience. But because of the foreign culture shock and the change of economy, social education and family education as the main ways of enculturation of traditional ethnic sports have been declining. At president, the main way of enculturation of traditional sports is school education. School education is a high level conscious enculturation with certain coercion in terms of contents, methods and aims. In order to achieve fairy result, traditional ethnic sports education has to explore more ways of enculturation. We need to know that the influence of culture upon individual is realized through both of the overt and covert ways. In this case, the enculturation in school education should reflect the two features of overtness and covertness. The overt ways in traditional ethnic sports education are mainly presented in the form of teaching and learning activities within class. The scope of covert ones is wider, containing the traditional ethnic sports in traditional festivals, the shows of the folk sports artisans, intercollegiate competitions of traditional ethnic sports, etc. We should integrate the overtness and covertness and expand the ways of enculturation. We also should create a good situation of traditional ethnic sports and make sure that the learning subjects can obtain nourishment at any time in any places so that we can realize the profound and far-fetched function of enculturation of traditional ethnic sports or else it will become the nostalgia of epoch.

\section{Conclusion}

To sum up, Chinese traditional ethnic sports education is closely connected with characteristics of the idea of modern Ecologic Education. After the analysis and argumentation, this article provides the very direction of the teaching model of Chinese traditional ethnic sports education under the view of Ecologic Education, which is pursuing life education full of spirituality, focusing on the active construction of knowledge and exploring mul- 
tiple ways of enculturation.

\section{Fund}

This research was supported by China National Social Science Fund.

\section{Project}

China national Social Science Fund Project (Sport) (12BTY021) and General Research program of fundamental Science Research in High Education (Swu1409182).

\section{References}

Bogdan, R. C., \& Biklen, S. K. (2003). Qualitative Research of Education: An Introductive to Theories and Methods (4th ed.). Boston: Allyn and Bacon.

Doll Jr., W. E. (2000). Post-Modern Perspective on Curriculum (pp. 53). Beijing: Beijing Education Publishing House.

Liu, T. F. (2000). Life Affect and Educational Solicitude. Teacher Education Research, 6, 30.

Rolston, H. (2000). Environmental Ethics: Duties to and Values in the Natural World (pp. 14-15). Yang, T. J. (Trans.), Beijing: China Social Science Press.

Schumacher, E. F. (1984). Small Is Beautiful (pp. 66). Beijing: Commercial Press.

$\mathrm{Su}$, X. G. (1998). The Ecologic Crisis and the Transvaluation of Western Culture. Journal of Peking University (Philosophy and Social Science), 1, 63-70.

Sun, J. Y., \& Li, Y. K. (2010). Co-Existence Education: The Compulsory Choice under Cultural Un-Balance, an Anthropological Study of the Hei Yi Zhuang Nationality in Napo County. Journal of Guangxi Normal University (Philosophy and Social Science Edition), 5, 7.

Teng, S. Y. (2006). Description of Artistic Society: The Pioneering Symposium on Artistic Education (pp. 86). Nanjing: Nanjing Press.

White, L. (1993). The Historical Roots of Our Ecologic Crisis. In I. Barbour (Ed.), Western Man and Environmental Ethics: Attitudes towards Nature and Technology (pp. 18). Massachusetts: Addison Wesley Publishing Company.

Zhu, D. Q., \& Peng, M. (2009). The Evolvement of the View of Knowledge and the Choice of Teaching Models. Journal of Teaching and Management, 10, 3-5. 
Scientific Research Publishing (SCIRP) is one of the largest Open Access journal publishers. It is currently publishing more than 200 open access, online, peer-reviewed journals covering a wide range of academic disciplines. SCIRP serves the worldwide academic communities and contributes to the progress and application of science with its publication.

Other selected journals from SCIRP are listed as below. Submit your manuscript to us via either submit@scirp.org or Online Submission Portal.
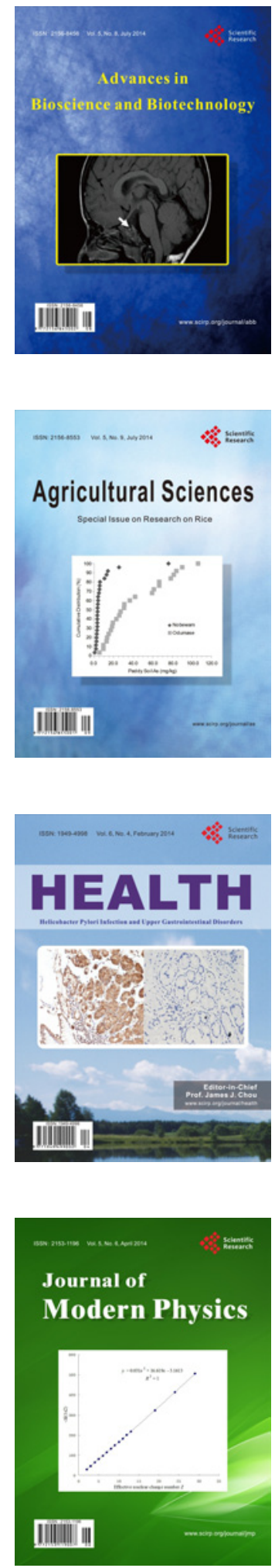
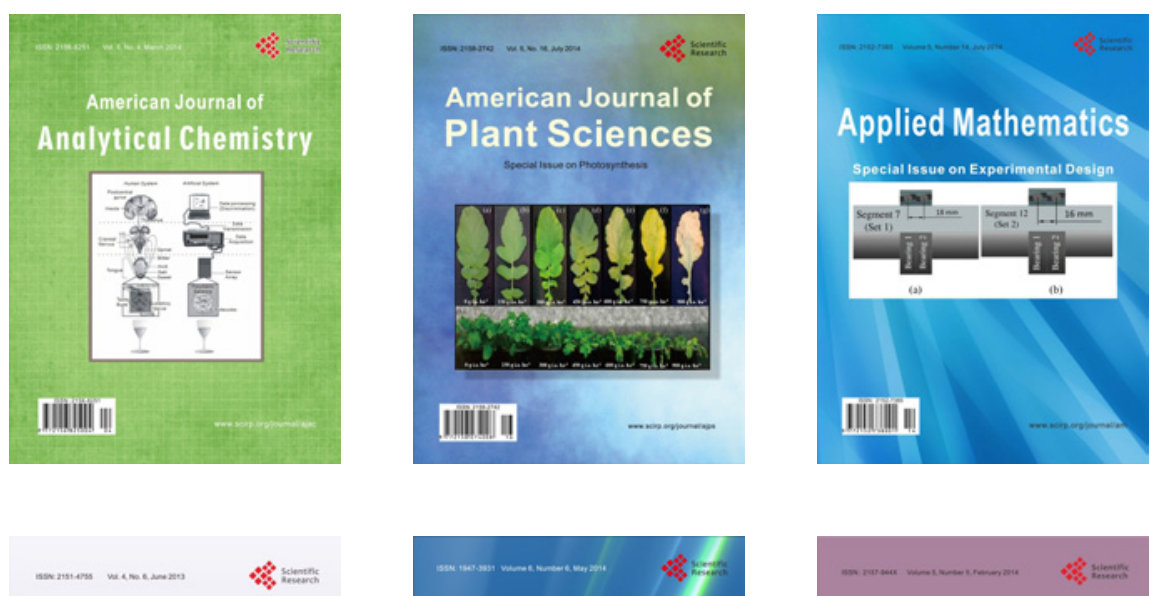

Creative Education
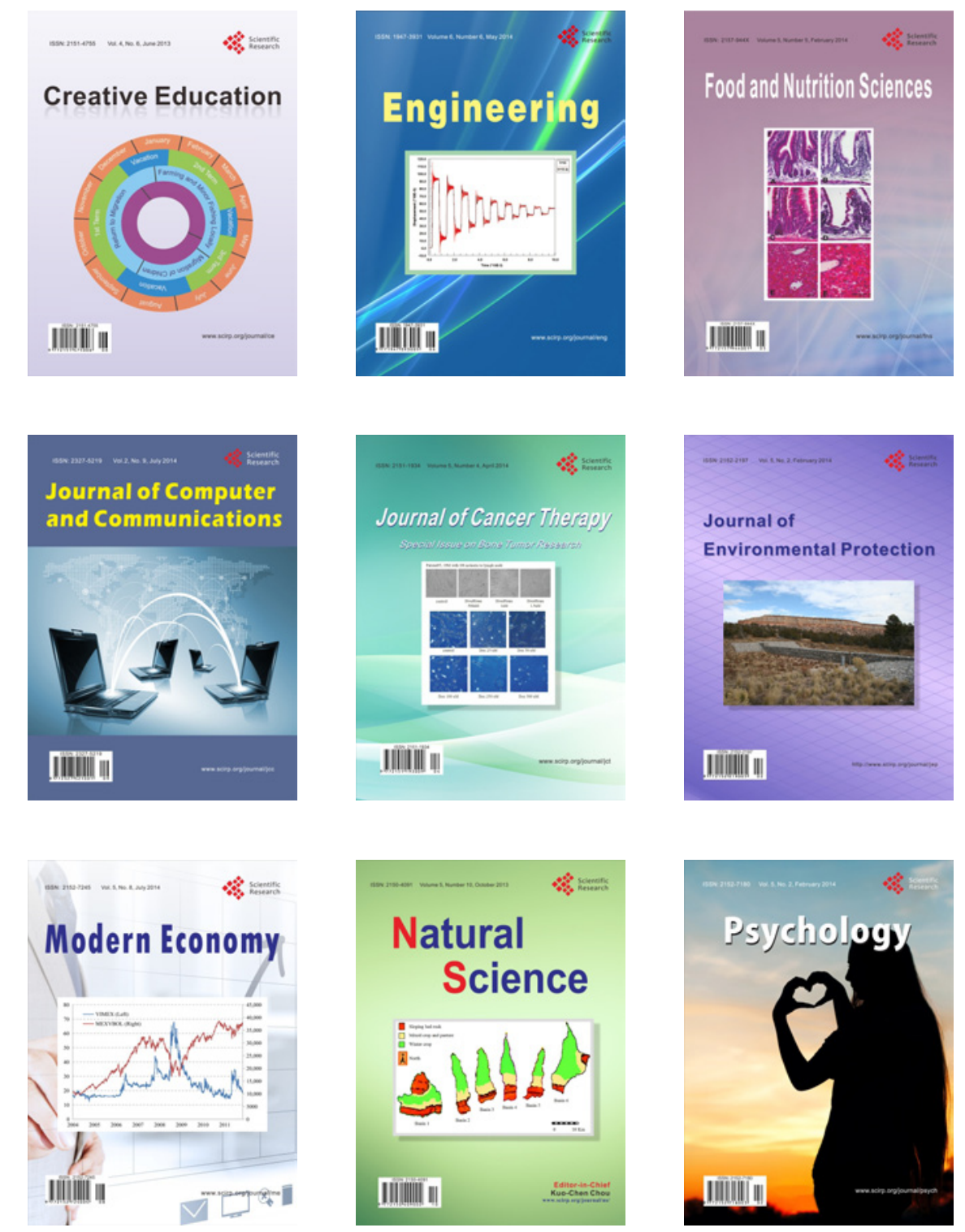